\title{
Optimal Administration Frequency of Cisplatin Concurrently With Radical Radiotherapy in the Definitive Treatment of Locally Advanced, Inoperable Squamous Cell Cancer of the Head and Neck. Still Obscured by Clouds?
}

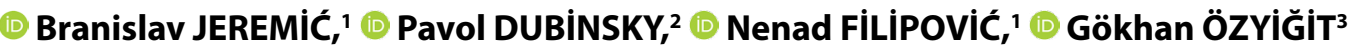 \\ 'Department of Oncology, Bio IRC, R\&D Center for Biomedical Research, Kragujevac-Yugoslavya \\ ${ }^{2}$ Department of Radiation Oncology, East Slovakia Institute of Oncology, Kosice-Slovakya \\ ${ }^{3}$ Department of Radiation Oncology, Haceteppe University, School of Medicine, Ankara-Turkey
}

\begin{abstract}
SUMMARY
Here we present a summary of existing evidence from meta-analyses and systematic reviews in the setting of locally advanced, inoperable squamous cell cancer of the head and neck, treated with radical radiotherapy and concurrent cisplatin therapy either weekly or every 3 weeks. Taken together, the data seem to indicate that there is no difference in major outcomes, including toxicity. However, caution in the interpretation of the data should be exercised due to poor quality of original studies, none of which was a prospective randomized phase III trial. Practicing clinicians should continue using their best judgment about the most appropriate treatment option in this setting, taking into account both the existing evidence and also various patient and tumor characteristics.
\end{abstract}

Keywords: Cisplatin; head and neck cancer; locally advanced disease; radiotherapy.

Copyright $\odot$ 2019, Turkish Society for Radiation Oncology

\section{Introduction}

Optimal treatment of patients with locally advanced squamous cell head and neck cancer (LA SCC H\&N) is one of the major challenges in H\&N oncology. While selected patients are treated with surgery and postoperative radio (chemo) therapy (RT-CHT), the vast majority of patients are deemed inoperable from the start. In such cases, combined RT-CHT has been practiced for decades. An extensive body of data within metaanalyses based on individual patient data enabled the investigation of the optimal sequence administration of the two treatment modalities. It was shown that neither induction CHT followed by RT or RT followed by adjuvant $\mathrm{CHT}$ offered any benefit over locoregional (in this case exclusive) RT. The only benefit was seen with concurrent RT-CHT, with the following magnitude: $6.5 \%$ absolute 5 -year survival benefit with the hazard ratio of 0.81 and $95 \%$ confidence intervals (CI) $0.74-$ $0.86(\mathrm{p}<0.0001)$. [1] Importantly, the same benefit was observed irrespectively of the type of RT used (conventional or altered fractionated) or whether postoperative RT had been used. Regarding the CHT issues, there were no differences between the single-agent and mufti-agent CHT, although in the single-agent group of trials, platinum-based regimens were found to be more effective than any other single-agent regimen. Unfortunately, this meta-analysis did not provide solid data on superiority of the type of the administration and the single or total dose of any of the used singleagent platinum regimens concurrent with radical RT. 
The issue of optimal administration of RT and CDDP in the definitive treatment remained unsolved, despite the fact that doses of $100 \mathrm{mg} / \mathrm{m}^{2}$ applied every 3 weeks were both suggested and largely practiced $[2,3]$ in the past three decades. In recent years, however, we have seen the introduction of a weekly administration of CDDP, mostly at a dose of $40 \mathrm{mg} / \mathrm{m}^{2}$, expecting to lead to less toxicity and potentially better (if not the same) radiosensitization, ultimately leading to a better therapeutic ratio. Unfortunately, high-quality and multiple prospective randomized trials (RCTs) investigating the issue of concurrent use of weekly vs. CDDP and RT applied every 3 weeks are strikingly lacking. This may be one the reasons why several meta-analyses and systematic reviews had been performed in recent years.

The last few years witnessed several attempts to address the issue of optimal administration of CDDP concurrently with radical RT. There are currently four meta-analyses/systematic reviews (Table 1) that should have provided a detailed, both quantitative and qualitative, synthesis of the existing data.[4-7] The data from the most recent study by Sturz et al. from 2019 [8] are the same as ones published originally in 2017.[5] Different time periods focused upon in these meta-analyses naturally resulted in a different number and type of studies included (main and separate analysis), and consequentially a different patient number, unfortunately not always specified. Additionally, the level of evidence stemming from included studies greatly diverged regarding various pretreatment (e.g..., diagnostic and staging criteria used in different time periods; inclusion of NPC) and treatment (e.g..., accelerated RT; total CDDP doses only when $>180 \mathrm{mg} / \mathrm{m}^{2}$; a weekly dose ranging from $20 \mathrm{mg} / \mathrm{m}^{2}$ to 50 $\mathrm{mg} / \mathrm{m}^{2}$ ). In addition, inconsistent reporting was one of the main concerns. One may, therefore, not be surprised to observe a great diversity between these four metaanalyses, none of which provided individual patient data.

In spite of these shortcomings, it is remarkable to observe that there is no significant difference in not only OS, but LRFS, PFS, and RR as well. Regarding toxicity, while Guan et al.[4] and Mohamed et al.[7] found no difference in any of documented toxicities, Jacinto et al.[6] found Grade $>3$ mucositis significantly more frequent in weekly CDDP, but only in a single RCT (using postoperative RT-CHT), while there was no difference in six retrospective studies using concurrent RT-CHT alone. In Sturz et al.[5], the administration of CDDP every 3 weeks led to significantly more leucopenia, neutropenia, $\mathrm{N} \& \mathrm{~V}$ and nephrotoxicity, with no difference in incidence rates of stomatitis and mucositis. The only study that found the 3-weekly regimen less toxic was that of Guan et al.[4], but only when high-grade mucositis in nonNPC treated with RT-CHT alone was considered sepa- rately from those of NPC cases. Taken all the available data from these four meta-analyses, and as an attempted summary, the existing evidence likely points toward similarity between the two CDDP regimens in this setting.

While proponents and practitioners of weekly CDDP may instantly jump at our conclusions as additional justification supporting their view, we would call for a cautious interpretation of the existing data. The lack of high-quality prospective phase III RCT are not only badly needed, but meta-analyses rarely can control for the lack of it when using the data from retrospective studies with their inherent biases and frequently poor quality which never, therefore, provide relief to that painful situation. Frequently we do not get even a hint to many issues we believe are of paramount importance for the future optimization of RT-CHT. They include, but are not limited to

1. Demystification of the nature and mechanisms of radiosensitization of weekly vs. 3-weekly CDDP given concurrently with radical RT (standard or altered fractionation) from the standpoint of both pharmacokinetics and pharmacodynamics, that is, which of the two regimen produces more effective radiosensitization $[9,10]$

2. Optimal total cumulative dose of CDDP given concurrently with radical RT [11]

3. Taking into account the promising results of using extreme CDDP fractionation, that is, daily low-dose CDDP given with either radical standard [12] or hyperfractionated RT [13], including a possibility of replacing CDDP with carboplatin (CBDCA) [11] at least when CDDP administration is prohibited

4. Observed difference between HPV- and HPV+ oropharyngeal patients (not subject of any of these meta-analyses), an information supporting the pathway to de-escalation of the treatment, which may be both feasible and effective [14];

5. Magnitude of the effect of impact of the p16 status due to the indication $\mathrm{p} 16+$ OPC patients may achieve superior results when compared to p16- patients [15] 6. A better definition of the place and role of altered fractionated regimens and novel RT techniques [16] We are aware that these concerns are floating around the world and that researchers are trying to actively contribute to this field by producing high-quality prospective RCTs, which remain our best tool to obtain highlevel evidence to be used in medicine. We are, however, are also certain that daily clinical practices would largely be governed by each patient coming to the treating physician, bearing its own mix of patient and tumor characteristics of the unique disease influencing the final decision about preferred regimen. Again, they include, but are not limited to the following: 

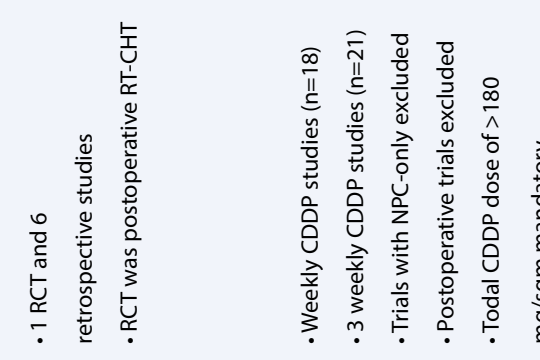

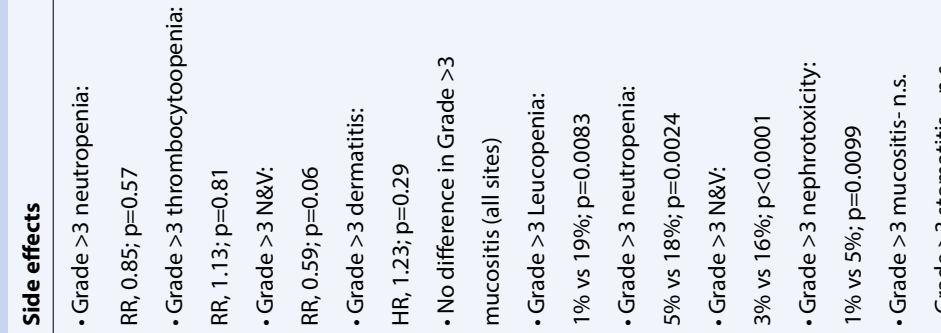
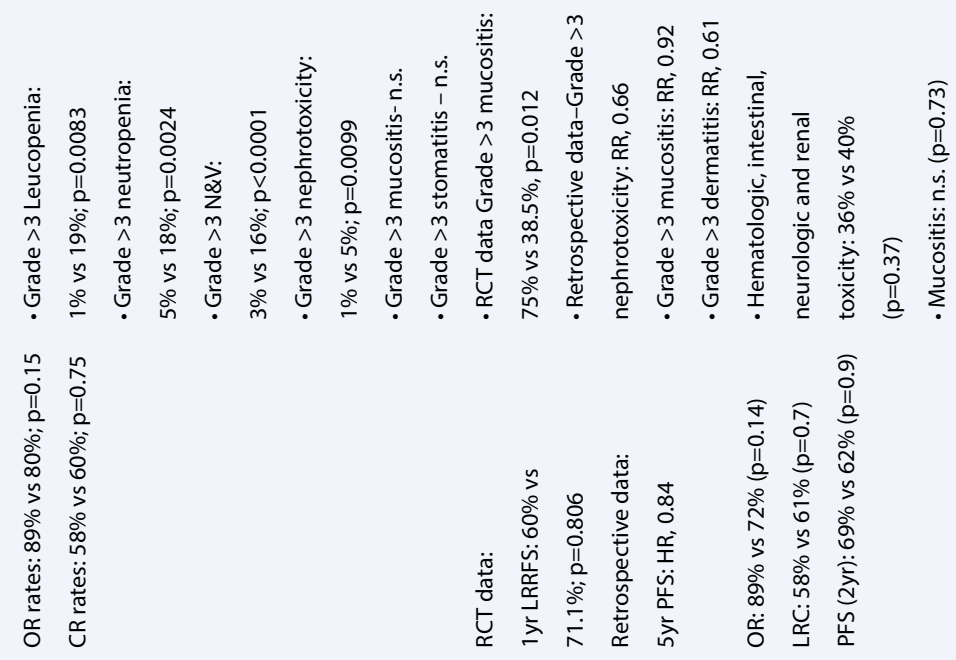

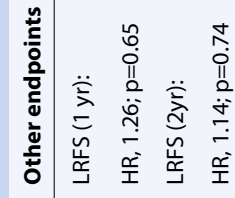
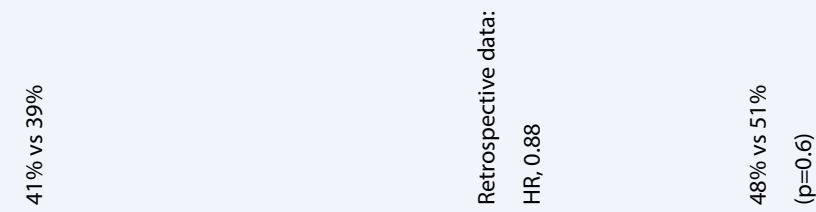

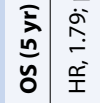
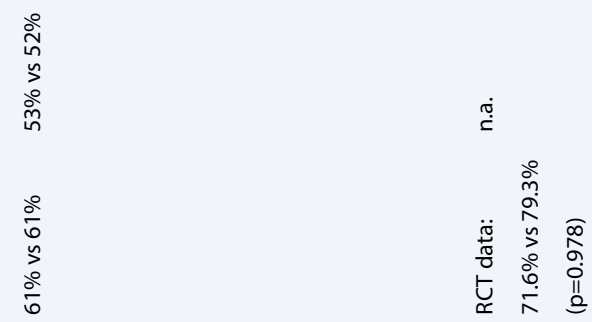

$\stackrel{\oplus}{\check{\varepsilon}}$
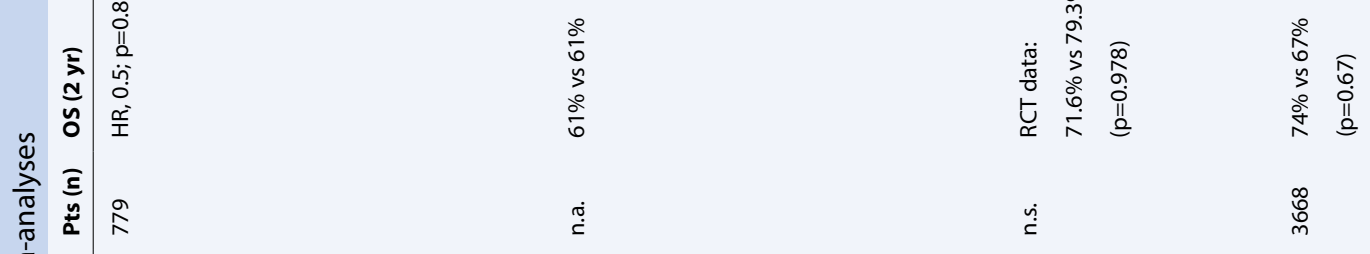

$\stackrel{\dot{s}}{\check{c}}$

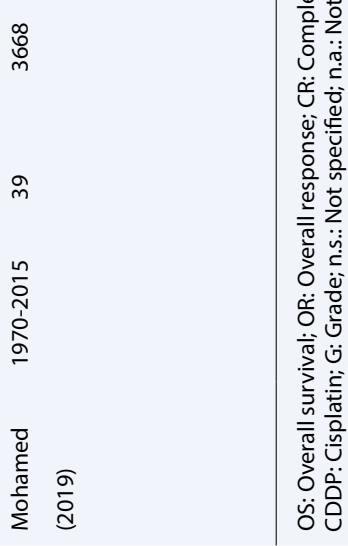

范

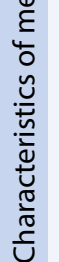

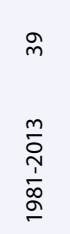

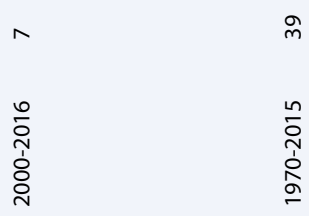

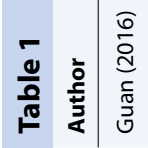

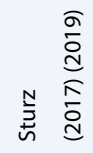

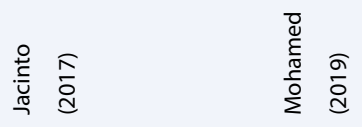


1. Elderly and/or frail patients, alcohol and/or tobacco consumers, and those with impaired kidney function will likely be advised for weekly CDDP administration.

2. Individuals with more advanced (higher) $\mathrm{T}$ and/or $\mathrm{N}$ tumors will likely continue to be advised for the CDDP administration every 3 weeks.

Hence, various medical and non-medical factors may govern the final decision about the best applicability of one of the two regimens. Involved physician's clinical expertise; however, remains crucial, and hopefully, still, based on the highest level of evidence that exists.

Peer-review: Externally peer-reviewed.

Conflict of Interest: Authors declared no conflicts of interest.

Financial Support: This work was partially funded by the grants from the Serbian Ministry of Education, Science and Technological Development III41007, ON174028.

\section{References}

1. Pignon JP, le Maître A, Maillard E, Bourhis J; MACHNC Collaborative Group. Meta-analysis of chemotherapy in head and neck cancer (MACH-NC): an update on 93 randomised trials and 17,346 patients. Radiother Oncol 2009;92(1):4-14.

2. Adelstein D, Gillison ML, Pfister DG, Spencer S, Adkins D, Brizel DM, et al. NCCN Guidelines Insights: Head and Neck Cancers, Version 2.2017. J Natl Compr Canc Netw 2017;15(6):761-70.

3. Ang KK, Chen A, Curran WJ Jr, Garden AS, Harari PM, Murphy BA, et al. Head and neck carcinoma in the United States: first comprehensive report of the Longitudinal Oncology Registry of Head and Neck Carcinoma (LORHAN). Cancer 2012;118(23):5783-92.

4. Guan J, Zhang Y, Li Q, Zhang Y, Li L, Chen M, et al. A meta-analysis of weekly cisplatin versus three weekly cisplatin chemotherapy plus concurrent radiotherapy (CRT) for advanced head and neck cancer (HNC). Oncotarget 2016;7(43):70185-70193.

5. Szturz P, Wouters K, Kiyota N, Tahara M, Prabhash $\mathrm{K}$, Noronha V, et al. Weekly Low-Dose Versus Three-Weekly High-Dose Cisplatin for Concurrent Chemoradiation in Locoregionally Advanced Non-Nasopharyngeal Head and Neck Cancer: A Systematic Review and Meta-Analysis of Aggregate Data. Oncologist 2017;22(9):1056-66.

6. Jacinto JK, Co J, Mejia MB, Regala EE. The evidence on effectiveness of weekly vs triweekly cisplatin concurrent with radiotherapy in locally advanced head and neck squamous cell carcinoma (HNSCC): a systematic review and meta-analysis. Br J Radiol 2017;90(1079):20170442.

7. Mohamed A, Twardy B, Zordok MA, Ashraf K, Alkhoder A, Schrapp K, et al. Concurrent chemoradiotherapy with weekly versus triweekly cisplatin in locally advanced squamous cell carcinoma of the head and neck: Comparative analysis. Head Neck 2019;41(5):1490-8.

8. Szturz P, Wouters K, Kiyota N, Tahara M, Prabhash K, Noronha V, et al. Low-Dose vs. High-Dose Cisplatin: Lessons Learned From 59 Chemoradiotherapy Trials in Head and Neck Cancer. Front Oncol 2019;9:86.

9. Vermorken JB, van der Vijgh WJ, Klein I, Gall HE, van Groeningen CJ, Hart GA, et al. Pharmacokinetics of free and total platinum species after rapid and prolonged infusions of cisplatin. Clin Pharmacol Ther 1986;39(2):136-44.

10. Bartelink H, Kallman RF, Rapacchietta D, Hart GA. Therapeutic enhancement in mice by clinically relevant dose and fractionation schedules of cis-diamminedichloroplatinum (II) and irradiation. Radiother Oncol 1986;6(1):61-74.

11. Strojan P, Vermorken JB, Beitler JJ, Saba NF, Haigentz M Jr, Bossi P, et al. Cumulative cisplatin dose in concurrent chemoradiotherapy for head and neck cancer: A systematic review. Head Neck 2016;38 Suppl 1:E2151-8.

12. Jeremic B, Shibamoto Y, Stanisavljevic B, Milojevic L, Milicic B, Nikolic N. Radiation therapy alone or with concurrent low-dose daily either cisplatin or carboplatin in locally advanced unresectable squamous cell carcinoma of the head and neck: a prospective randomized trial. Radiother Oncol 1997;43(1):29-37.

13. Jeremic B, Shibamoto Y, Milicic B, Nikolic N, Dagovic A, Aleksandrovic J, et al. Hyperfractionated radiation therapy with or without concurrent low-dose daily cisplatin in locally advanced squamous cell carcinoma of the head and neck: a prospective randomized trial. J Clin Oncol 2000;18(7):1458-64.

14. Ang KK, Harris J, Wheeler R, Weber R, Rosenthal DI, Nguyen-Tân PF, et al. Human papillomavirus and survival of patients with oropharyngeal cancer. $\mathrm{N}$ Engl J Med 2010;363(1):24-35.

15. Ang KK, Sturgis EM. Human papillomavirus as a marker of the natural history and response to therapy of head and neck squamous cell carcinoma. Semin Radiat Oncol 2012;22(2):128-42.

16. Ang KK, Zhang Q, Rosenthal DI, Nguyen-Tan PF, Sherman EJ, Weber RS, et al. Randomized phase III trial of concurrent accelerated radiation plus cisplatin with or without cetuximab for stage III to IV head and neck carcinoma: RTOG 0522. J Clin Oncol 2014;32(27):2940-50. 